\title{
MOBILIDADE URBANA EM PRESIDENTE PRUDENTE: O TRANSPORTE COLETIVO E SUAS POSSIBILIDADES
}

Poliana de Oliveira Basso', Sibila Corral de Arêa Leão Honda².

'Discente do curso de Arquitetura e Urbanismo da Universidade do Oeste Paulista - UNOESTE. ${ }^{2}$ Docente e Coordenadora do curso de Arquitetura e Urbanismo da Universidade do Oeste Paulista - UNOESTE.

\section{RESUMO}

O intenso crescimento urbano no Brasil, a partir da década de 1960, trouxe às cidades, e principalmente aos grandes centros urbanos, um novo problema urbano: o sistema de mobilidade urbana de baixa qualidade e alto custo, que impactaram de forma negativa na vida da população e dos custos econômicos e ambientais para a cidade e a sociedade. O processo de urbanização está diretamente associado ao aumento do uso de veículos motorizados, principalmente dos individuais (motocicletas e automóveis), resultado de políticas públicas que priorizaram o investimento na indústria automobilística. A carência de mobilidade urbana aumentam as desigualdades sociais e geram externalidades negativas como: acidentes de trânsito, poluição, congestionamentos, entre outros. Em Presidente Prudente-SP já se verifica problemas urbanos relacionados à carência de mobilidade urbana. Assim, esta pesquisa visa a levantar as problemáticas e buscar soluções para tais, focando na melhoria e valorização do transporte coletivo como principal saída.

Palavras-chave: Mobilidade Urbana, Planejamento Urbano, Transporte Coletivo, Acessibilidade, Plano Diretor.

\section{INTRODUÇÃO}

O processo de urbanização no Brasil foi marcado pelo êxodo rural a partir da década de 1930, com a migração da área rural para área urbana, e reforçado pelo processo de industrialização na década de 1960, com seu pico na década de 1980, que transformou um país de características rurais em um país essencialmente urbano.

Em 1940, a população urbana no Brasil representava aproximadamente $25 \%$ do total, passando para mais de $75 \%$ no final da década de 2000 . O acelerado processo de urbanização requeria infraestrutura urbana e grandes investimentos estatais, porém, pouco se fez e não atingiu as necessidades, provocando uma nova realidade das cidades, que se encontravam com inchaço populacional e com acentuados problemas urbanos, como falta de habitações, carência de saneamento básico, deficiência do transporte público e desemprego (BASSUL, 2002; SILVA, 2003).

Atualmente, os centros urbanos continuam em acelerado processo de crescimento, e nos últimos anos, com o bom momento da economia brasileira e o estímulo da indústria automotiva, o número de carros particulares aumentam cada vez mais, desconfigurando, assim, o papel das cidades de proporcionar qualidade de vida e qualidade de circulaçãoa seus habitantes, 
intensificando os conflitos entre diferentes modos de deslocamento e gerando excessivos gastos econômicos, na tentativa de viabilizar o fluxo de veículos motorizados (DUARTE; LIBARDI; SÁNCHEZ, 2008).

A necessidade de movimento dos cidadãos depende de como a cidade está organizada espacialmente e ligada funcionalmente com as atividades de que se desenvolvem no espaço urbano. Essas duas esferas, organizacional e física, e suas contradições, atingem primeiramente as populações mais pobres e menos protegidas, onde a circulação e a acessibilidade ao espaço urbano são intensamente reduzidas (DUARTE; LIBARDI; SÁNCHEZ, 2008).

A perda da qualidade urbana deveria levar a uma revisão dos Planos Diretores, buscando privilegiar os pedestres e o transporte coletivo sobre o veiculo particular, sendo este o principal gerador de congestionamentos, prevendo a revitalização dos espaços públicos. Tendo como finalidade trazer vida a espaços urbanos que foram descaracterizados e desumanizados pela presença intensiva e excessiva dos automóveis particulares, além de melhorias das vias e facilidade de acesso aos espaços urbanos da população de classe baixa, o uso massivo do transporte coletivo é fundamental (DUARTE; LIBARDI; SÁNCHEZ, 2008).

Em Presidente Prudente-SP, o tema mobilidade urbana deve ser levantado, pois é possível verificar os problemas citados acima, embora em menor grau que nas grandes metrópoles.

A cidade teve um grande crescimento populacional entre os anos de 1960 a 1980, onde a infraestrutura não acompanhou esse processo. Hoje, Presidente Prudente é sede da 10a região do Estado de São Paulo, recebendo um grande fluxo de pessoas diariamente, além da própria população que é de mais de 200.000 habitantes (IBGE, 2010).

A falta de infraestrutura e de grandes vias de acesso, e o aumento excessivo de transporte privado, geram problemas de mobilidade urbana, principalmente em horários de picos, das $7 \mathrm{~h}$ às $9 \mathrm{~h}$ e das $17 \mathrm{~h}$ às $19 \mathrm{~h}$. Outro problema de mobilidade urbana nessa cidade deve-se à expansão territorial urbana, que ocorre de maneira dispersa, ocasionando problemas de mobilidade dos bairros localizados nos extremos da malha, que enfrentam diariamente a dificuldade ao acesso às áreas centrais, devido ao sistema falho de transporte coletivo.

Visto aos problemas levantados e à necessidade de condições adequadas de mobilidade para a população, o objetivo geral da pesquisa se constrói na análise da mobilidade urbana em conceito geral, buscando compreender o contexto na cidade de Presidente Prudente-SP, com foco nas problemáticas encontradas na cidade e suas necessidades, a fim de desenvolver um planejamento urbano, visando à melhoria da qualidade do espaço urbano e da mobilidade. 


\section{METODOLOGIA}

A metodologia seguida baseou-se em pesquisas bibliográficas, teorias e conceitos, a fim de se obter embasamento teórico sobre o tema; levantamentos históricos (documentos e imagens); análises comparativas sobre planejamento urbano, mobilidade urbana, e as leis que regularizam as políticas públicas, no âmbito municipal, estadual e federal, voltadas ao transporte coletivo; finalizando a pesquisa nas informações e embasamentos obtidos, por meio de interpretações dos autores.

\section{ASPECTOS DA MOBILIDADE URBANA}

O atendimento das necessidades sociais e econômicas das pessoas requer seu deslocamento no espaço, que podem ser feitos de diversas maneiras, podendo ser por meios não motorizados, caminhada ou uso da bicicleta, ou por meios motorizados, motocicletas, automóveis, ônibus, metrô, trem, entre outros. Estes deslocamentos são feitos com maior ou menor nível de conforto, conforme as condições específicas em que se realizam.

Os meios de deslocamento e de transporte não motorizados demandam menos gastos aos usuários e menos investimentos públicos, além de não causarem impacto ambiental e possibilitar melhores condições de vida urbana, não provocando congestionamentos e poluição. Já os meios de deslocamento e de transporte motorizados geram externalidades negativas, como a poluição sonora e atmosférica do ambiente urbano, acidentes de trânsito e congestionamentos (VASCONCELLOS; CARVALHO; PEREIRA, 2011).

Segundo Vasconcellos (2012), as formas de transportes podem ser classificadas de dois modos, sendo a primeira referente ao uso direto do transporte, como individual, que são as bicicletas, motocicletas e automóveis particulares, que permitem a pessoa viajar sozinha; ou coletivo, que são as vans, ônibus, trens, metrôs, onde várias pessoas usam simultaneamente. A outra classificação refere-se à natureza legal de cada forma de transporte, como privado, no caso as bicicletas, motocicletas e automóveis, sendo de uso privativo do proprietário; ou público, que são os meios de transportes que estão a disposição de qualquer pessoa, desde que seja pago, como no caso de mototáxis e táxis (público exclusivo), ônibus, trens e metrôs (público coletivo).

No Brasil, atualmente o sistema de transporte e mobilidade urbana se caracteriza pelo elevado uso do transporte motorizado individual. Em 2007, nas cidades com população acima de 60.000 habitantes, a frota de veículos circulando era de aproximadamente 30 milhões, sendo 15,2 milhões de automóveis e veículos comerciais leves (VASCONCELLOS; CARVALHO; PEREIRA, 2011). 
De acordo com o Sistema de Informações da ANTP (apud VASCONCELLOS; CARVALHO; PEREIRA, 2011), em 2007, a média de deslocamentos realizados era de $38 \%$ a pé, $27 \%$ por automóvel, e $29 \%$ por transporte coletivo. Identificando o intenso uso do transporte motorizado individual e, como consequência, o seus efeitos negativos à mobilidade urbana.

A facilidade de deslocamento possibilitada pelo automóvel motorizado fez com que ampliassem as aglomerações urbanas e aumentassem as distâncias, o que implica em maiores deslocamentos, tornando a população dependente dos veículos motorizados, levando à necessidade de investimentos em infraestrutura viária, e aumento dos veículos (BRASIL, 2007).

Embora não haja mais espaço fisico, os investimentos ainda se concentram no aumento da infraestrutura viária que permita maior mobilidade urbana. O fato é que esses investimentos incentivam o uso do automóvel motorizado, pois quanto mais vias se constroem, mais veículos entram em circulação, gerando uma situação contrária ao que se esperava, aumentando os problemas ao invés de solucioná-los (BRASIL, 2007; VASCONCELLOS, 2012).

Em Presidente Prudente-SP, foco desta pesquisa, o grande crescimento populacional, entre os anos de 1960 e 1980, o não acompanhamento da infraestrutura urbana, a dispersão da malha urbana, o aumento excessivo do transporte motorizado privado e a sistema inadequado de transporte coletivo, resultaram em grandes problemas de mobilidade urbana e acesso.

A cidade é alimentada por quatro vias principais: Av. Manoel Goulart, Av. Washington Luiz, Av. Coronel José Soares Marcondes e Av. Brasil (figura 1). Estas se cruzam formando o quadrilátero central, que é área onde há a maior concentração de comércio e serviço da cidade.

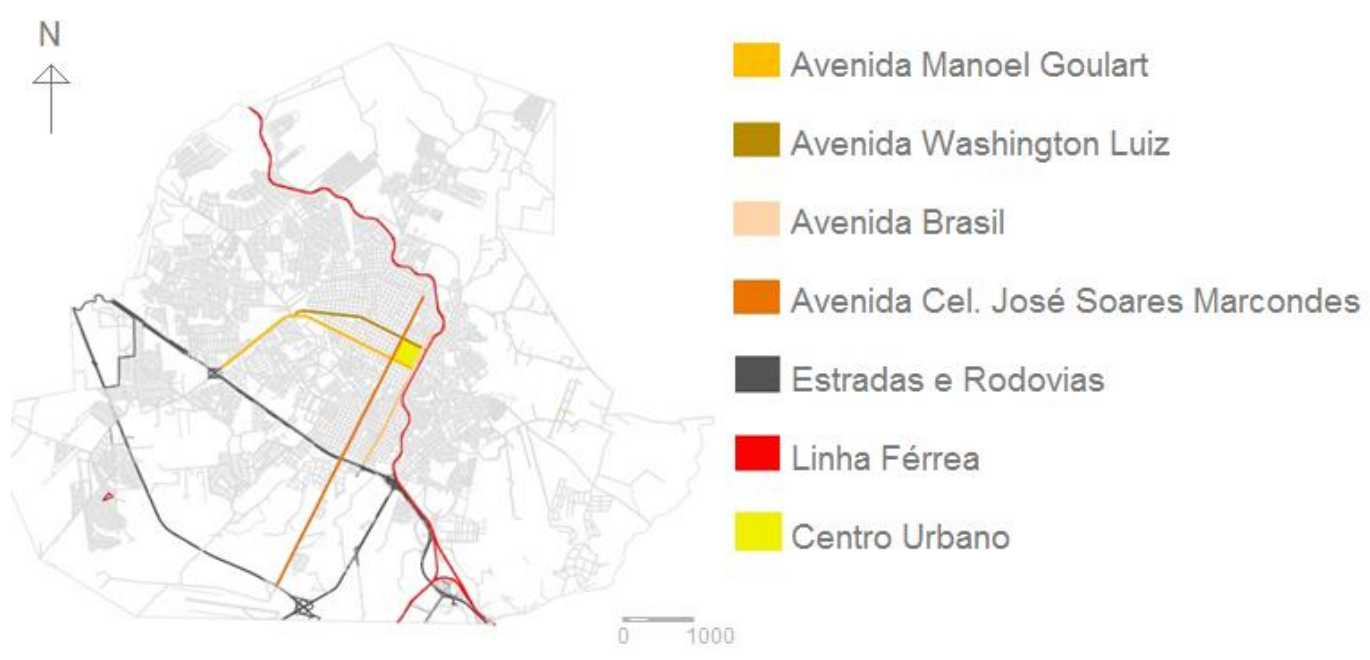

Figura 1. Planta urbana de Presidente Prudente - identificação das principais avenidas Fonte: Autora, 2013 sobre base: Mapa 2012, Prefeitura Municipal de Presidente Prudente. 
O sistema viário de Presidente Prudente não recebeu alterações com a evolução da cidade, e as vias principais são estreitas com faixa de estacionamento dos dois lados. $O$ fato de delas fazerem a ligação da área central às áreas periféricas acaba por receber um grande fluxo de automóveis, principalmente nos horários de pico, resultando em congestionamentos, e problemas e carências de mobilidade urbana, além de possíveis acidentes de trânsito.

A expansão da malha urbana trouxe dificuldade ao acesso dos moradores das áreas periféricas para as áreas centrais. As distâncias que deveriam ser encurtadas aumentaram com sua dispersão. A maioria dos conjuntos habitacionais e bairros de baixa renda foram implantados na franja urbana, assim como muitos dos condomínios fechados de alta e média-alta rendas, reforçando os problemas de mobilidade e de trânsito urbanos.

O transporte coletivo em Presidente Prudente é de concessão privada, sendo duas as empresas: a Transportes Coletivo Presidente Prudente (TCPP) e PrudenExpress. As linhas de ônibus fazem cobertura de grande parte da cidade, porém suas distribuições foram mal organizadas: não há linhas diretas para a área central; não há um eixo de linha rápida que sirva como distribuidora para as demais linhas; todas dão grandes voltas pelos bairros, aumentando seu tempo de viagem; há bairros não servidos por linhas de ônibus; há concentração de linhas passando pelos mesmos pontos; $100 \%$ das linhas passam por uma (ou mais) das quatro principais avenidas da cidade, dificultado ainda mais o fluxo nessas avenidas por serem estreitas e não estarem adequadas para atender o grande fluxo de ônibus; há apenas um terminal urbano, que se encontra na área central da cidade.

Observa-se que, havendo condições da população não utilizar transporte público nessa cidade, o faz. Dependendo de uma alteração na estrutura das linhas e de todo o planejamento de transporte público e restrição ao transporte particular, poderia haver uma mudança de cultura do carro particular e otimização de toda estrutura intra-urbana.

A retirada de parte das linhas das quatro principais avenidas e diversificação dessas linhas por outras vias, reduziria o impacto negativo existente; assim como mudança nos percursos nos bairros é fator fundamental para reduzir tempo de viagens e estimular o uso do transporte público.

O foco municipal não deve ser dado ao transporte particular, resultando em democratização dos serviços e dos espaços públicos, criando uma cidade mais justa a toda sua população. 


\section{CONSIDERAÇÕES FINAIS}

Este artigo é resultado de pesquisa efetuada na elaboração de trabalho de conclusão de curso em Arquitetura e Urbanismo, na Universidade do Oeste Paulista. Teve como objetivo principal levantar a discussão sobre os problemas urbanos que a cidade tem enfrentado, com foco na mobilidade por meio do transporte coletivo.

Após análises e pesquisas verificou-se que em Presidente Prudente-SP tem havido falta de planejamento urbano e omissão do governo municipal em relação ao trânsito e transporte, tendo levado à implantação do sistema do transporte coletivo de maneira deficitária, que, consequentemente, tornou-se responsável por grande parte dos problemas de mobilidade urbana.

A sua implantação de forma adequada, possibilitaria eficiência, rapidez, acessibilidade e também ajuda na mobilidade para toda a população urbana, com possibilidade em mudança de cultura do carro particular.

Entende-se, portanto, que o início da solução não está no investimento em ampliações de vias, devem-se incentivar os modos de transporte coletivo, assim como os não motorizados, e voltar os investimentos públicos e privados para eles.

A cidade e as pessoas que a habitam devem ser valorizadas, aumentando a qualidade de vida, de modo a não ver mais o automóvel particular como único meio de transporte.

\section{REFERÊNCIAS}

BRASIL. Ministério das Cidades. Secretaria Nacional de Transporte e da Mobilidade Urbana. "PlanMob - construindo a cidade sustentável". no1. Caderno de referência para elaboração de plano de mobilidade urbana. 2007.

CARVALHO, S. N. de. Estatuto da Cidade: aspectos políticos e técnicos do plano diretor. São Paulo Pespec. Vol. 15, n.4. São Paulo. Oct./Dec. 2001. Disponível em: <http://dx.doi.org/10.1590/S010288392001000400014>. Acesso em: 09 abr. 2013.

DUARTE, F.; LIBARDI, R.; SÁNCHEZ, K.. Introdução a Mobilidade Urbana. Curitiba: Juruá, 2008. SILVA, E. R. da. O Movimento Nacional pela Reforma Urbana e o Processo de Democratização do Planejamento Urbano no Brasil. São Carlos: UFSCar, 2003. (Dissertação de Mestrado).

VASCONCELLOS, E. A. Mobilidade Urbana e Cidadania. Rio de Janeiro: SENAC NACIONAL, 2012.

VASCONCELLOS, E. A.; CARVALHO, C. H. R. de; PEREIRA, R. H. M. Transporte e Mobilidade Urbana. Brasília, DF: CEPAL. Escritório no Brasil/IPEA, 2011. 